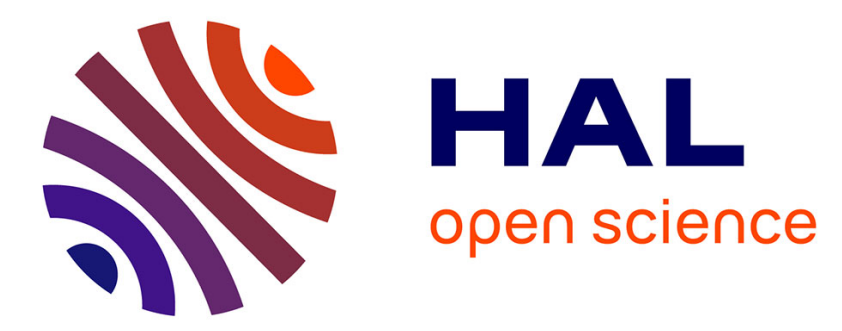

\title{
Combining 3D digitizing data and architectural modelling to simulate shoot growth and geometry in apple.
}

\author{
Benoit Pallas, Jérome Ngao, M. Saudreau, Evelyne Costes
}

\section{To cite this version:}

Benoit Pallas, Jérome Ngao, M. Saudreau, Evelyne Costes. Combining 3D digitizing data and architectural modelling to simulate shoot growth and geometry in apple.. X International Symposium on Modelling in Fruit Research and Orchard Management, Jun 2015, Montpellier, France. , Acta Horticulturae, 1160, pp.28, 2015, 10.17660/ActaHortic.2017.1160.5 . hal-01269059

\section{HAL Id: hal-01269059 \\ https://hal.science/hal-01269059}

Submitted on 2 Jun 2020

HAL is a multi-disciplinary open access archive for the deposit and dissemination of scientific research documents, whether they are published or not. The documents may come from teaching and research institutions in France or abroad, or from public or private research centers.
L'archive ouverte pluridisciplinaire HAL, est destinée au dépôt et à la diffusion de documents scientifiques de niveau recherche, publiés ou non, émanant des établissements d'enseignement et de recherche français ou étrangers, des laboratoires publics ou privés.

$$
\text { Copyright }
$$




\title{
Combining 3D digitizing data and architectural modelling to simulate shoot growth and geometry in apple.
}

\author{
B. Pallas ${ }^{1}$, J. Ngao ${ }^{2}$, M. Saudreau ${ }^{2}$, E. Costes ${ }^{1}$
}

\author{
${ }^{1}$ INRA, UMR AGAP, Montpellier, France \\ ${ }^{2}$ INRA, UMR PIAF, Clermont-Ferrand, France
}

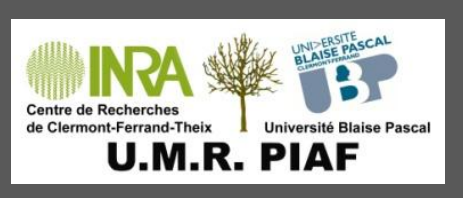




\section{Objectives and context}

Digitizing is precise but time consuming:

- Few trees measured

- But digitizing can be performed on trees in agronomic conditions

- Can be used as reference for model validation

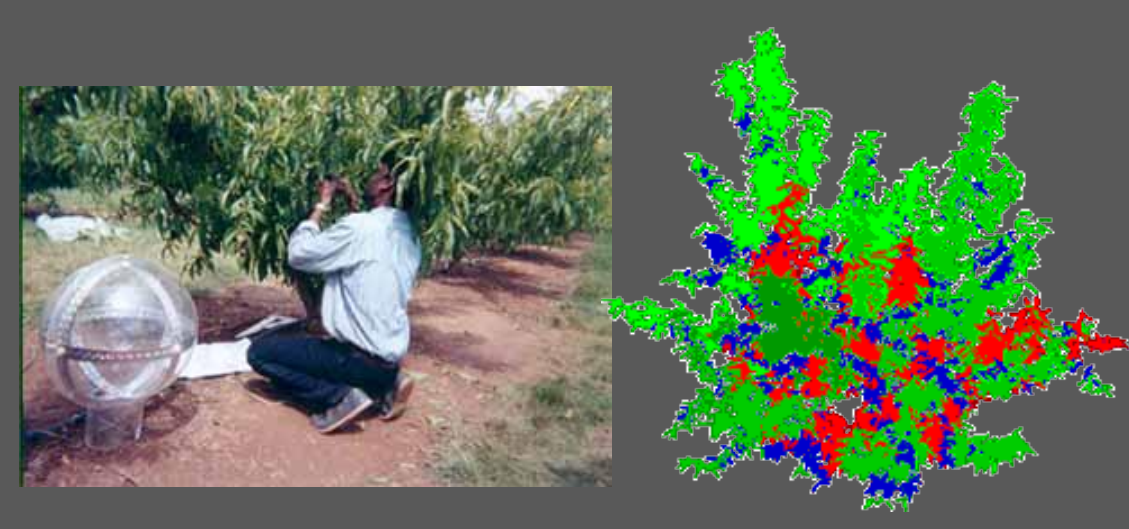

Simulations of tree development (MappleT) form 1yo to $x$-y-old based on Markov models for GU successions and branching

- Computational time can be long for running several consecutive years

- Do not integrate the agronomic conditions (especially pruning)

- Difficulty to compare the random trees generated with real trees.

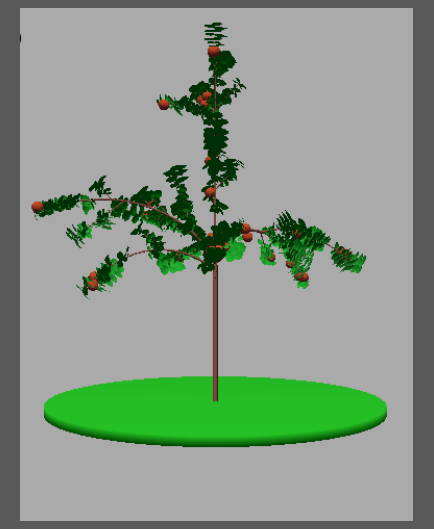

Costes et al., 2008

\section{Objectives.}

- Use digitized trees at cycle $n$ as input data and built tree at cycle $n+x$ using statistical Markov models for terminal and axillary bud fates and apple tree geometrical characteristics

- Build a flexible tool for 3D reconstruction and evaluation of light interception of trees at any stage 


\section{Modelling description - digitizing data as input files}

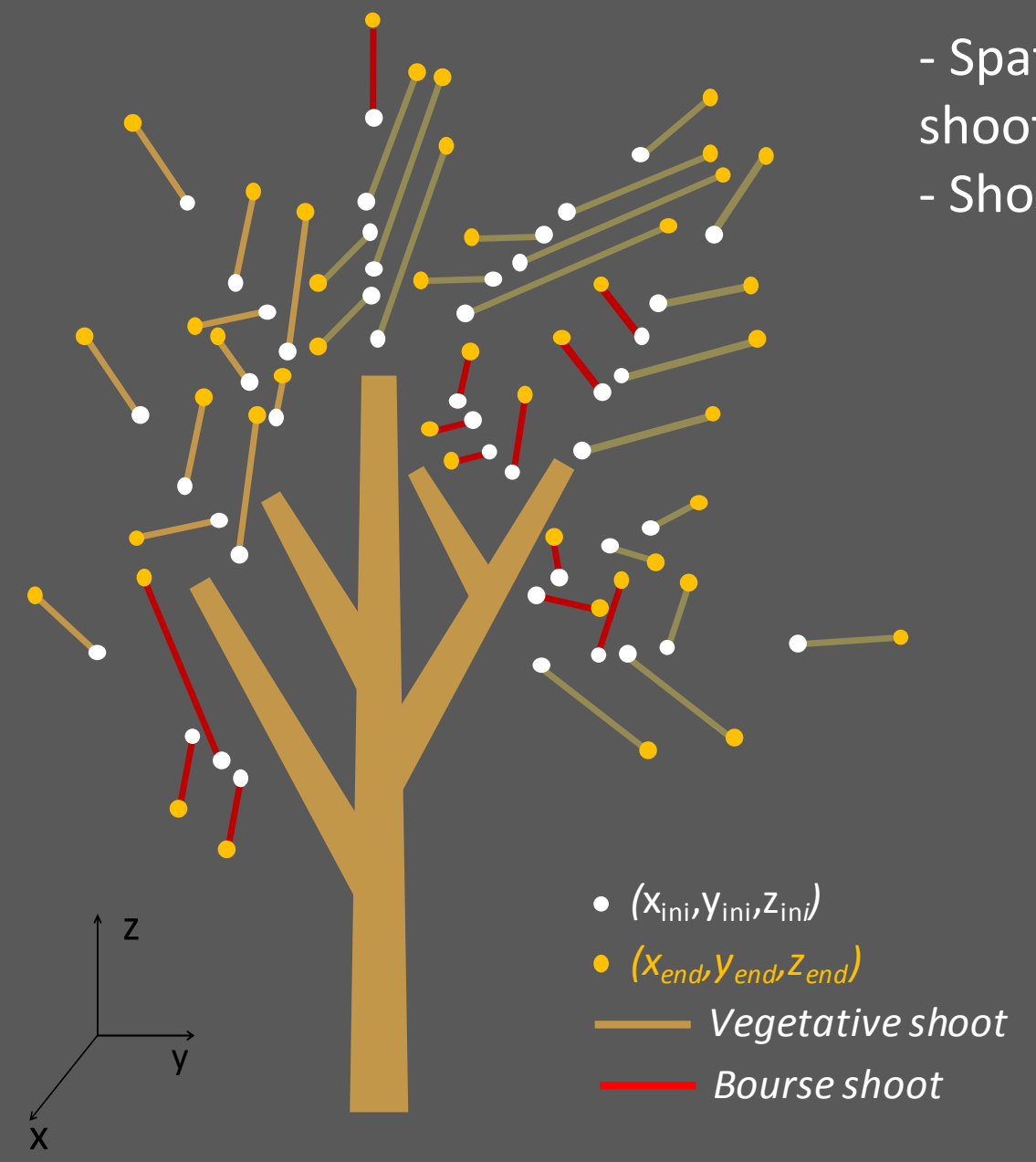

- Simplified digitizing methodology.

(e.g. Massonet et al. 2008)

- Spatial coordinates of beginning and end of 1 year old shoot.

Shoot type (vegetative, bourse shoot, inflorescence)

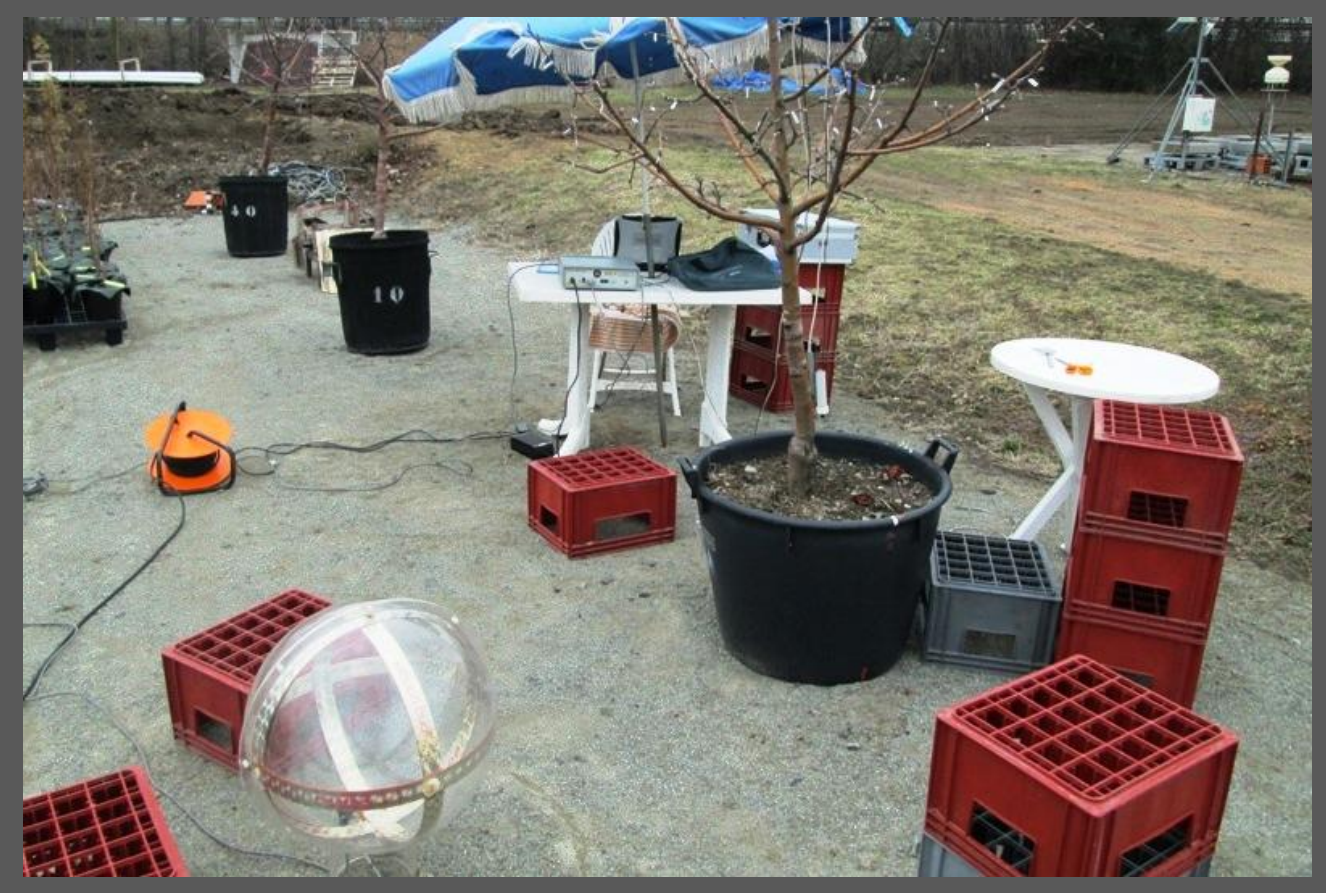




\section{Modelling description - simulation of growing unit succession}
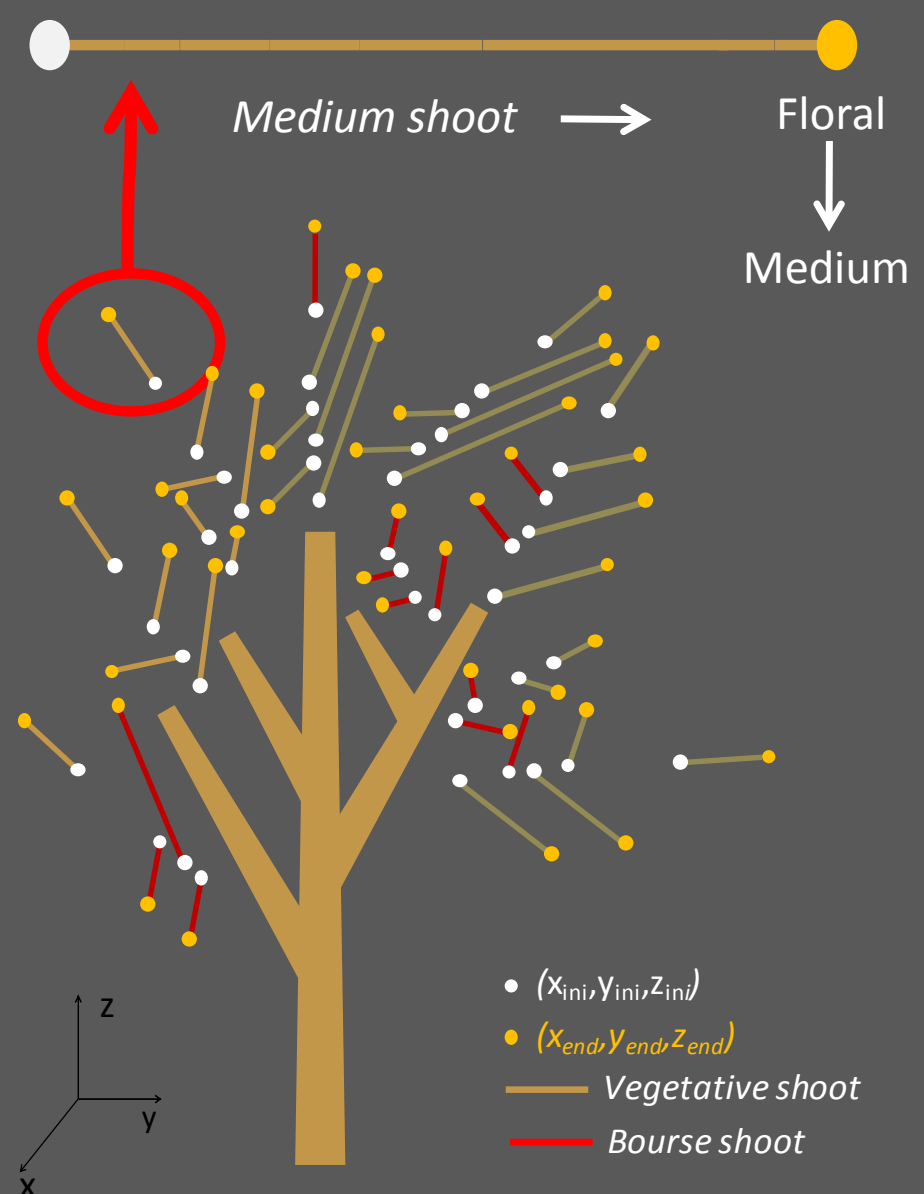

- Discretization of GU types based on length (short, medium, long).

- First order transition probabilities after vegetative growth units.

- Second order transition probabilities after reproductive growth units. (fruit number is then computed using a fruit set parameter)

Representation of the transition probability matrix (from Costes and Guédon, 2012).

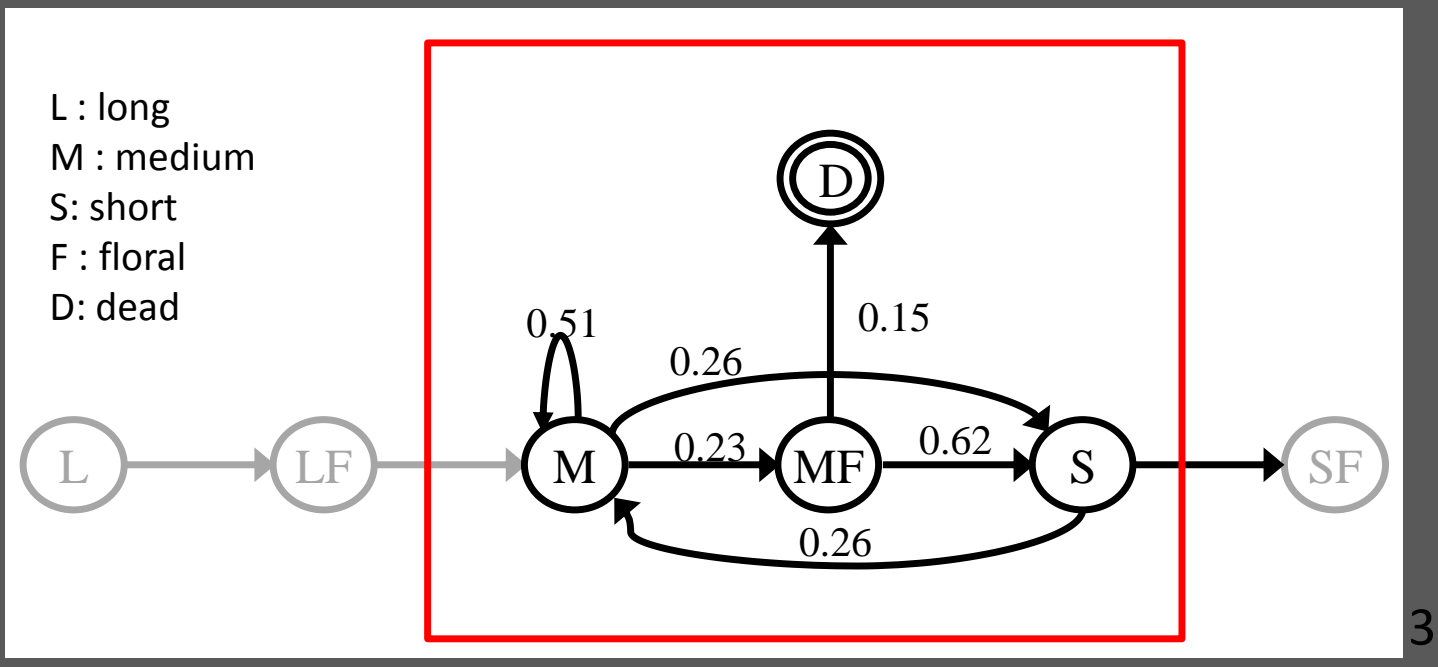




\section{Modelling description - simulation of branching pattern}

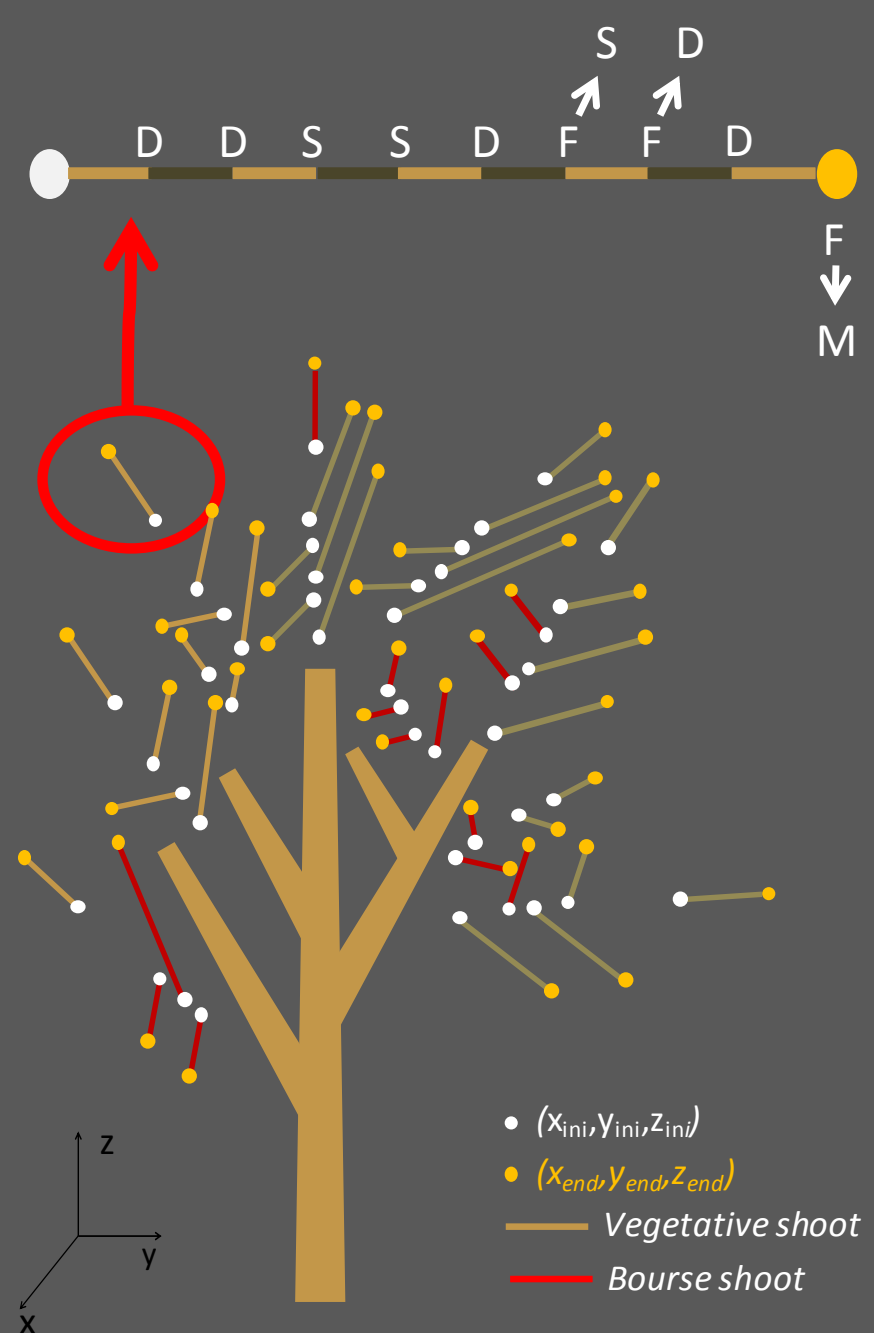

- Hidden semi Markov chain formalisms (from Guédon et al., 2001; Costes and Guédon, 2002; Costes et al. 2008)

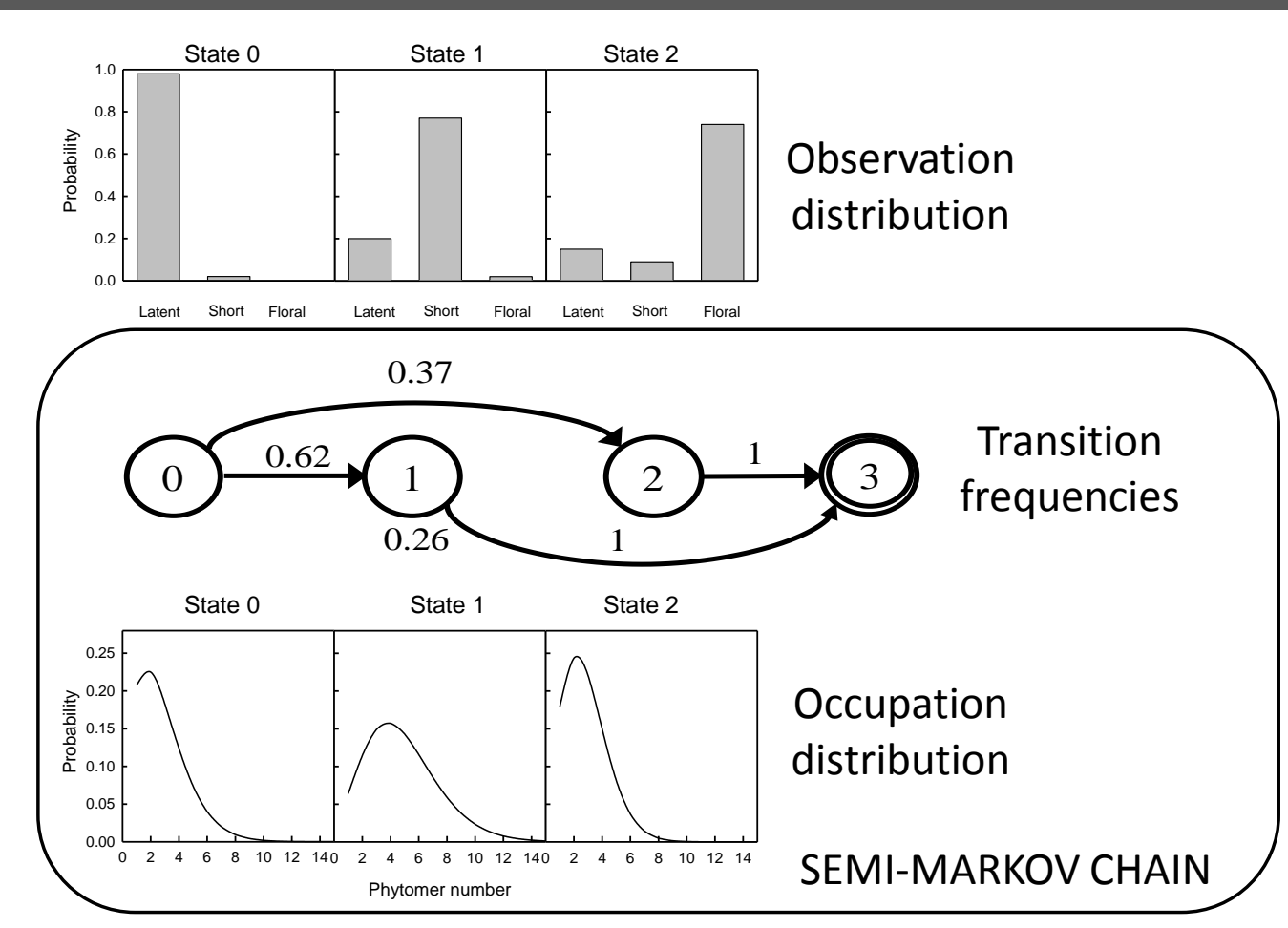

DDDSSSSDD, DDDSSSSS, DDDDSSSSD, DDFFFF, DDDDFFF, DDDDFFFF, DDDS DSSDSS, DDD
Generation of a collection of random sequences

- Random choice of a sequence corresponding to the length of the GU

- GU internode number computed from allometric relationships. 


\section{Modelling description - geometrical features}

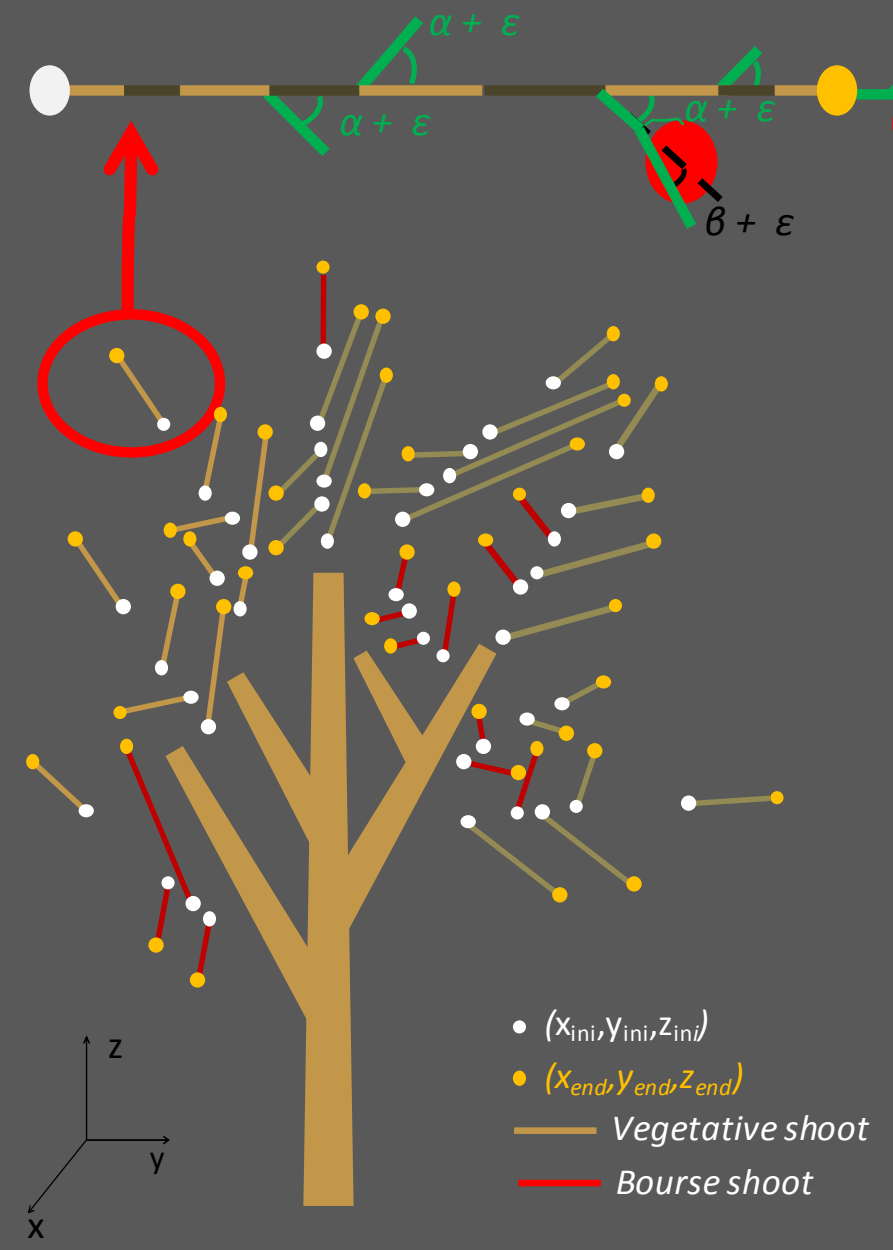

$\nabla \bar{B}+\bar{\varepsilon}$

- Internode profile to locate all the branches along the 1 year old branch

- Shoot geometry :

- Branching angle for branches and after an inflorescence (mean value and standard deviation)

- no shoot bending
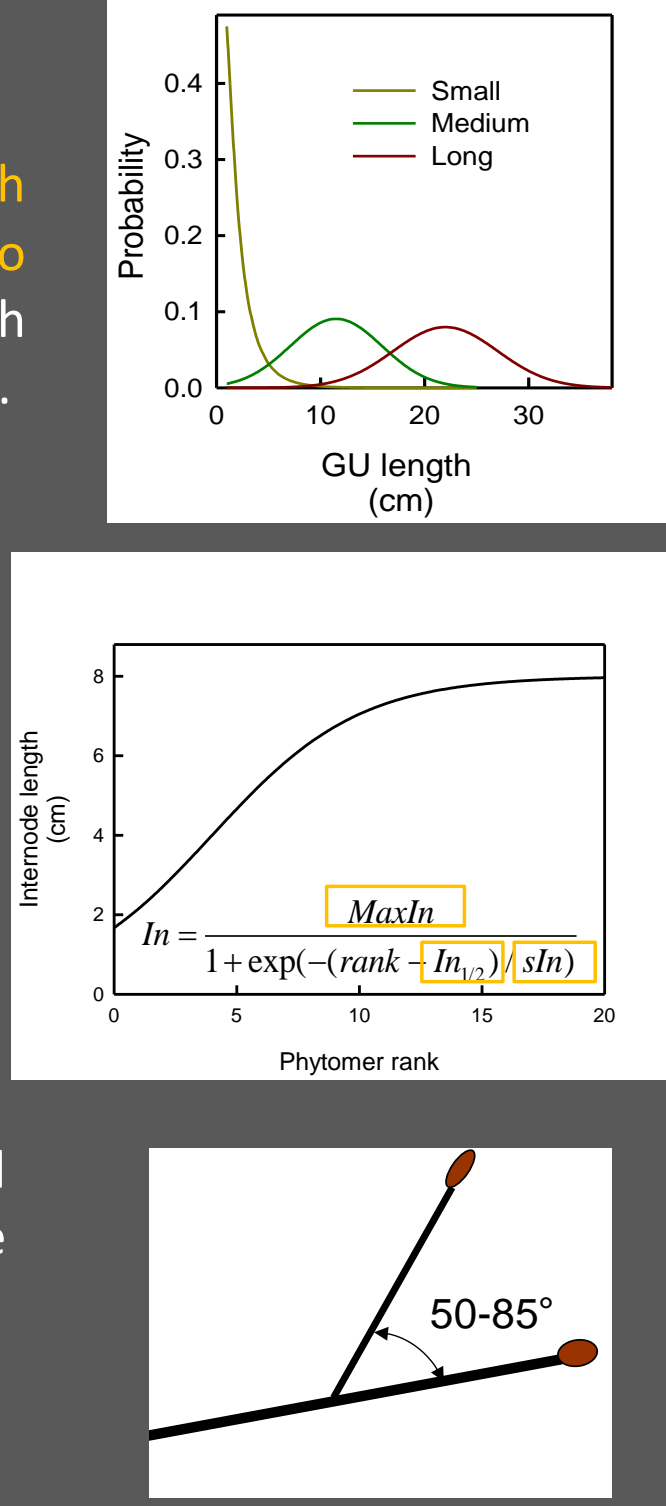


\section{Modelling description - simulation of leaf distribution along shoots}

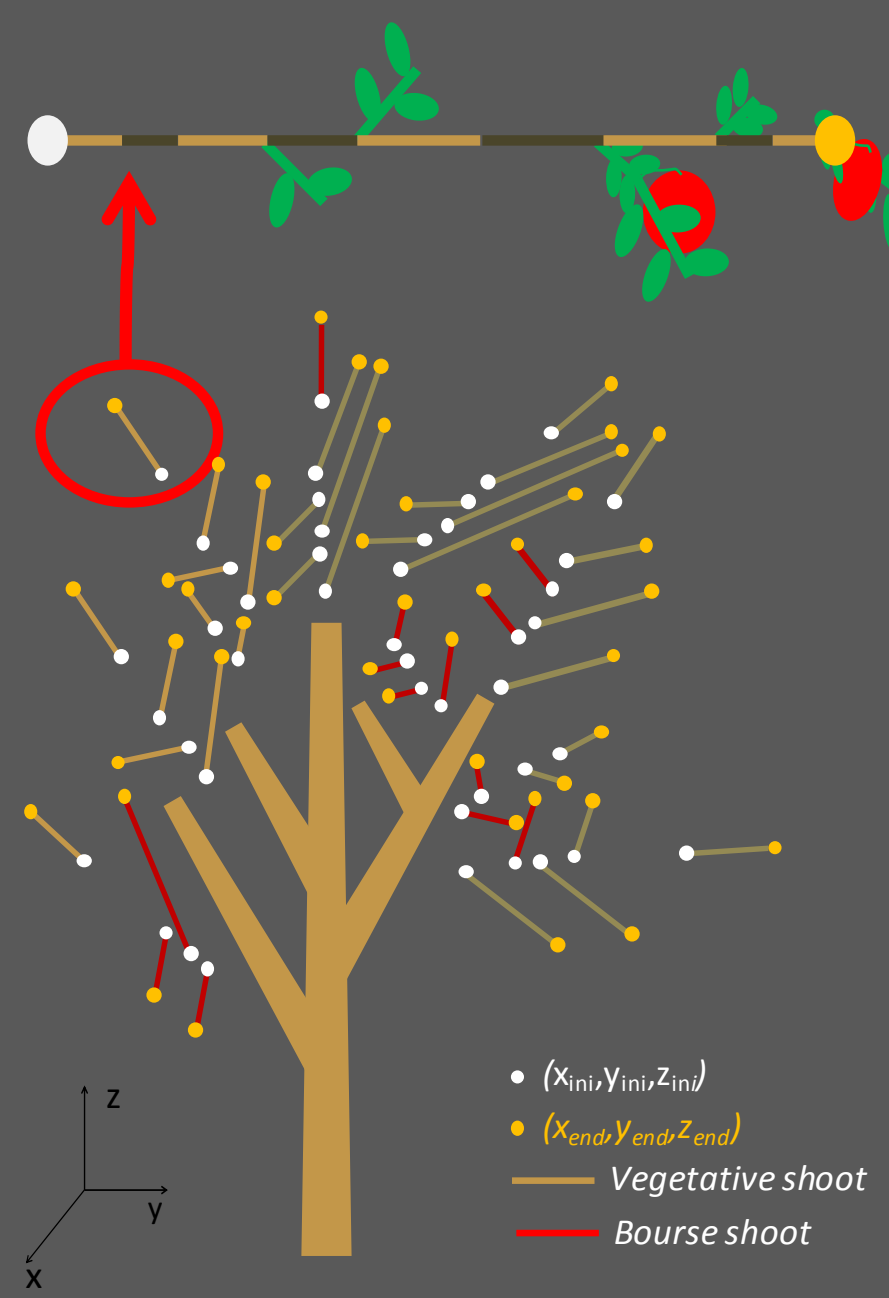

- Allometric relationships at shoot scale based on shoot length $\boldsymbol{L}$ (short, medium, long) and type, and at leaf scale (Sonohat et al., 2006).

- At shoot scale: total leaf surface area (TSA), number of leaves $(L N)$, internode length $(I N)$ distribution and leaf area distribution along shoot.

- At leaf scale: length, width, surface area and distributions of leaf rolling angle and leaf inclination angle.

Single leaf surface area (LS)

$$
L S=T S A / L N
$$

Single Leaf length $(L L)$ and width $(L W)$

$$
\begin{aligned}
& L L=f(L S) \\
& L S=f(L L)
\end{aligned}
$$

$>$ Leaf angles: Measurements of distributions of leaf rolling angle and leaf inclination angle by shoot type 


\section{Model calibration}

- Model calibrated on the 'Jubilé 'cultivar (9 trees), data collected from 2007 until 2013.

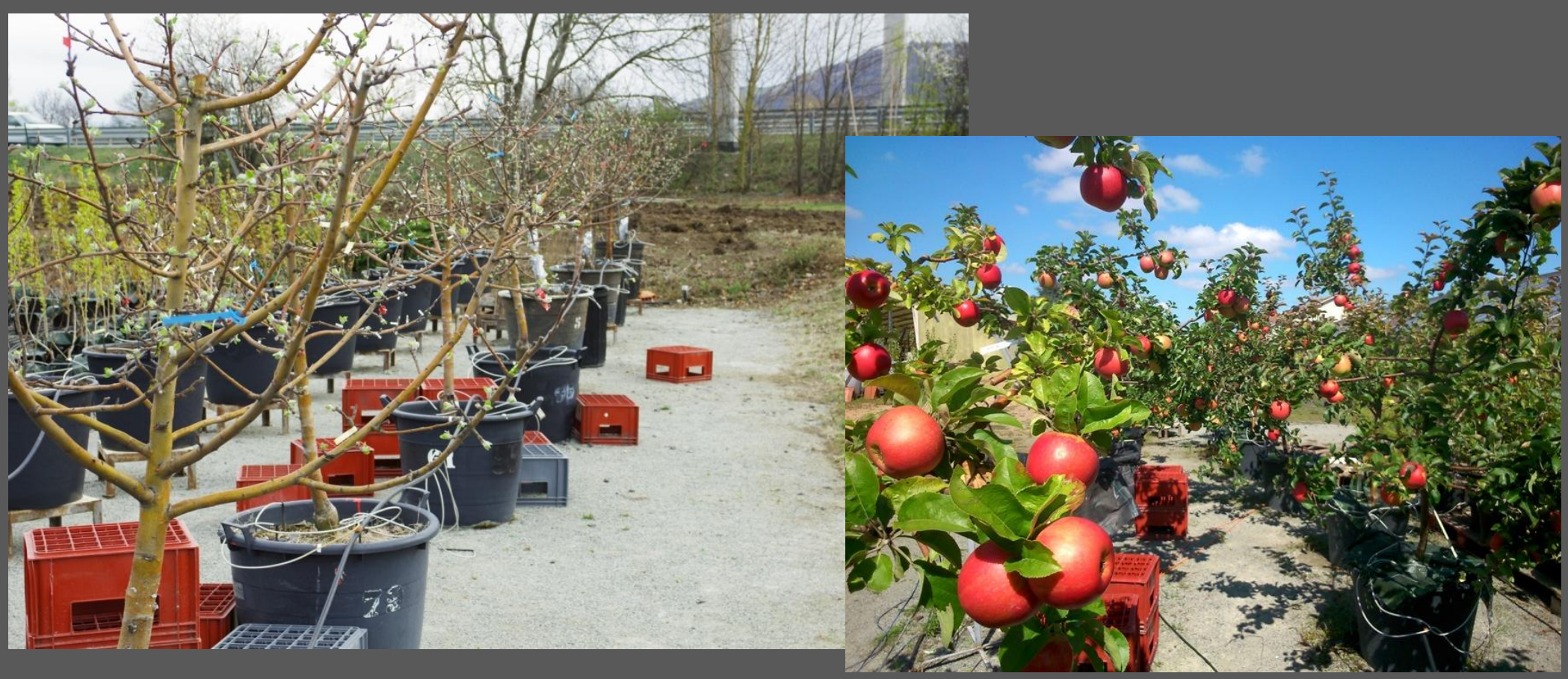

- Growth units succesion matrix estimated on sequences recorded on second and third order branches. (140 shoots)

-Geometrical features (branching angles, allometric relationships, length distribution) were recorded in 2013 on 8 years old trees.

- Fruit set was estimated on the 9 trees in 2013. 


\section{Model calibration}

- Calibration of the hidden semi Markov model.

- Performed on around 100 branching sequences collected in 2013 .

- Model estimation with openalea plateform.

- A unique model for each growth unit was used.

- Simple patterns were observed.

Type $1(51.8 \%)$ : $\stackrel{\text { Zone } 1}{\text { B B B B S B S S S }}$

Type $2(30.9 \%): \stackrel{\text { Zone } 1}{\text { B B B B F B F F F }}$

Type $3(17.4 \%)$ : S B S S S
$B$ : latent bud

S: short

F: floral
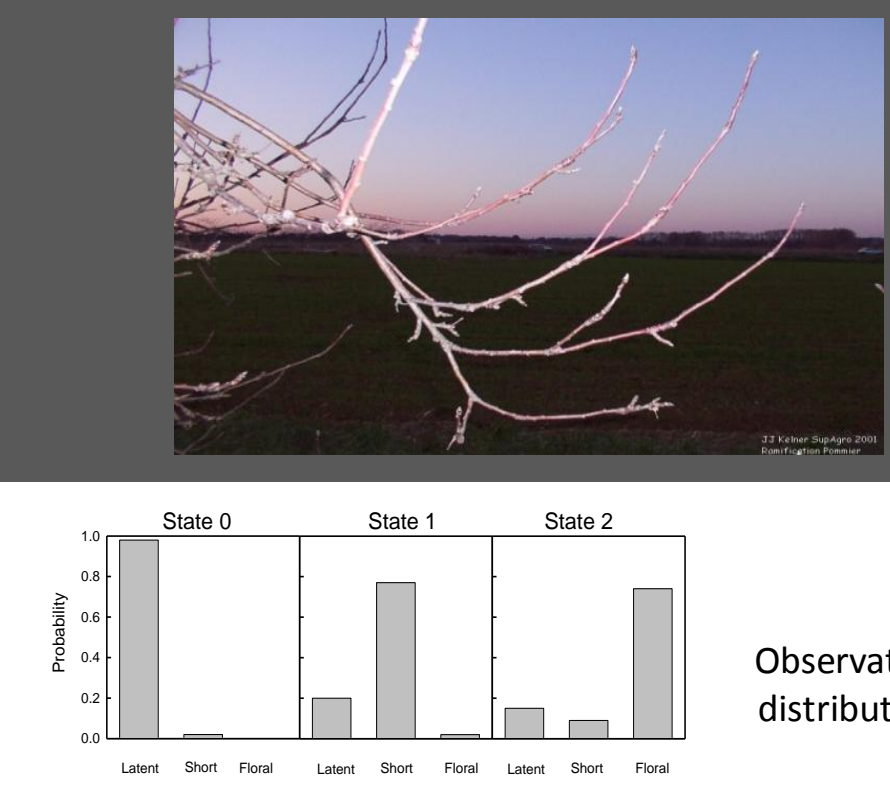

Observation distribution

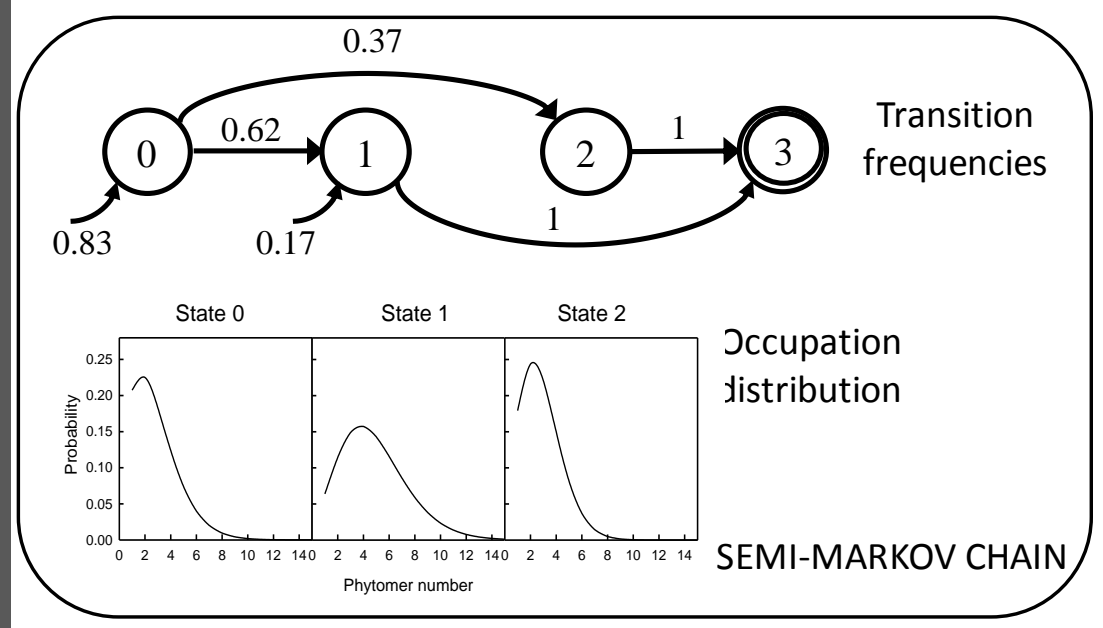

- Branching pattern only adapted for « small size GU » (old tree). 


\section{Model simulation and validation}

- 2 trees digitized in 2013 and 2014 (8 year-old).

- 2013 data were used as input files and simulations (15 random trees) were compared to 2014 data.

- A modeling framework coupling the 'simulation' model, a 3D visualization software and a light interception model (RATP, Sinoquet et al. 2001) was built.

- Validations were performed on shoot demography, leaf area distribution and light interception.

- Except for the probability of flowering occurrence (ON, OFF trees), all the parameters were identical for the two trees.
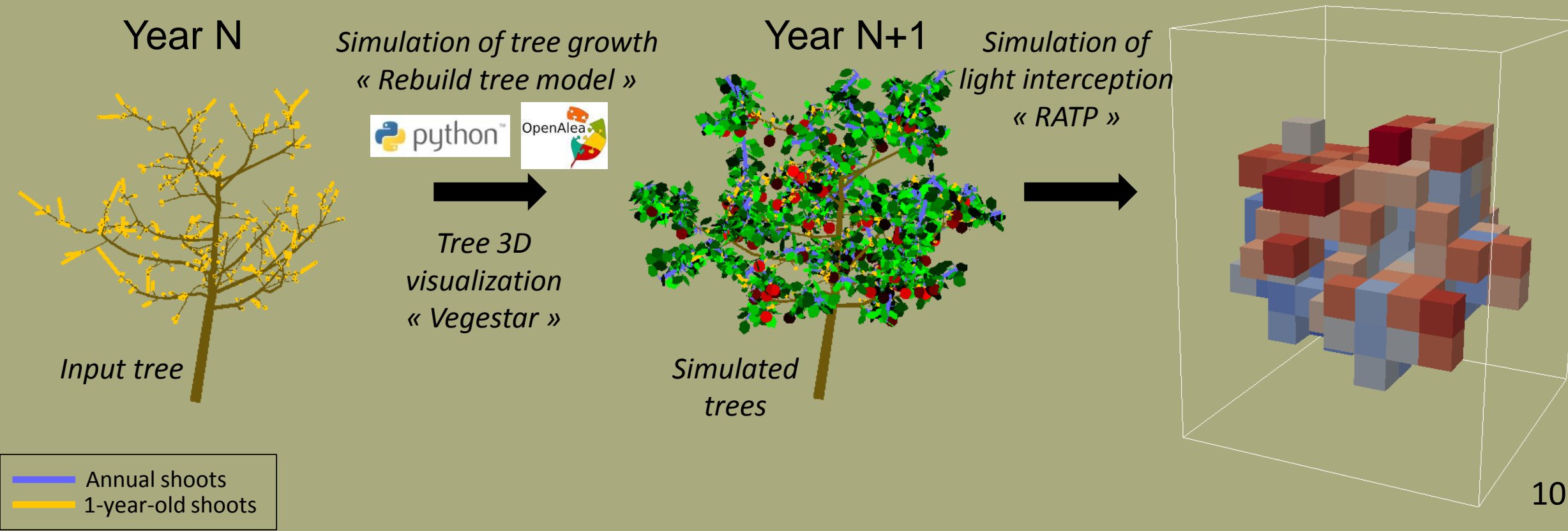


\section{Model validation, shoot demography and leaf area (tree 1)}

\section{- Observed tree}

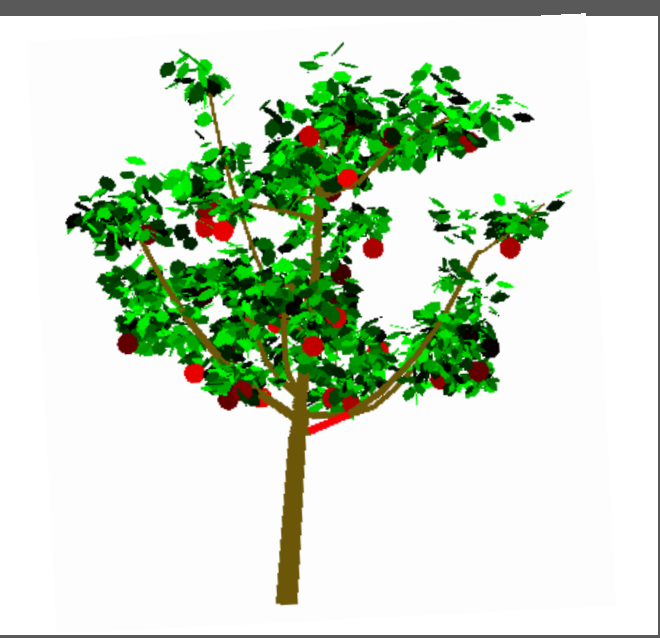

\begin{tabular}{|c|c|c|}
\hline & $\begin{array}{c}\text { Leaf area } \\
\left(\mathbf{m}^{\mathbf{2}} \mathbf{)}\right.\end{array}$ & $\begin{array}{c}\text { GU } \\
\text { number }\end{array}$ \\
\hline Observed & 3.39 & 439 \\
\hline $\begin{array}{c}\text { Simulated } \\
(\mathrm{n}=15)\end{array}$ & $\begin{array}{c}3.17 \\
+/-0.28\end{array}$ & $\begin{array}{c}371 \\
+/-21.3\end{array}$ \\
\hline
\end{tabular}

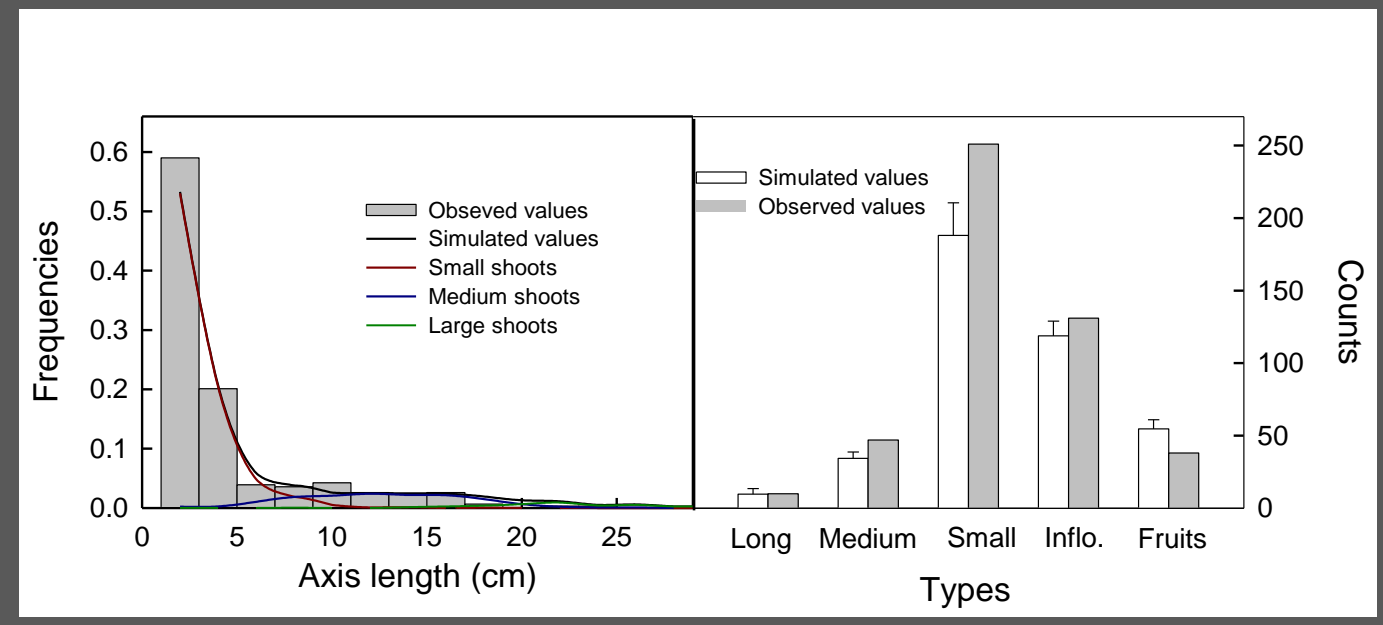

- Simulated trees

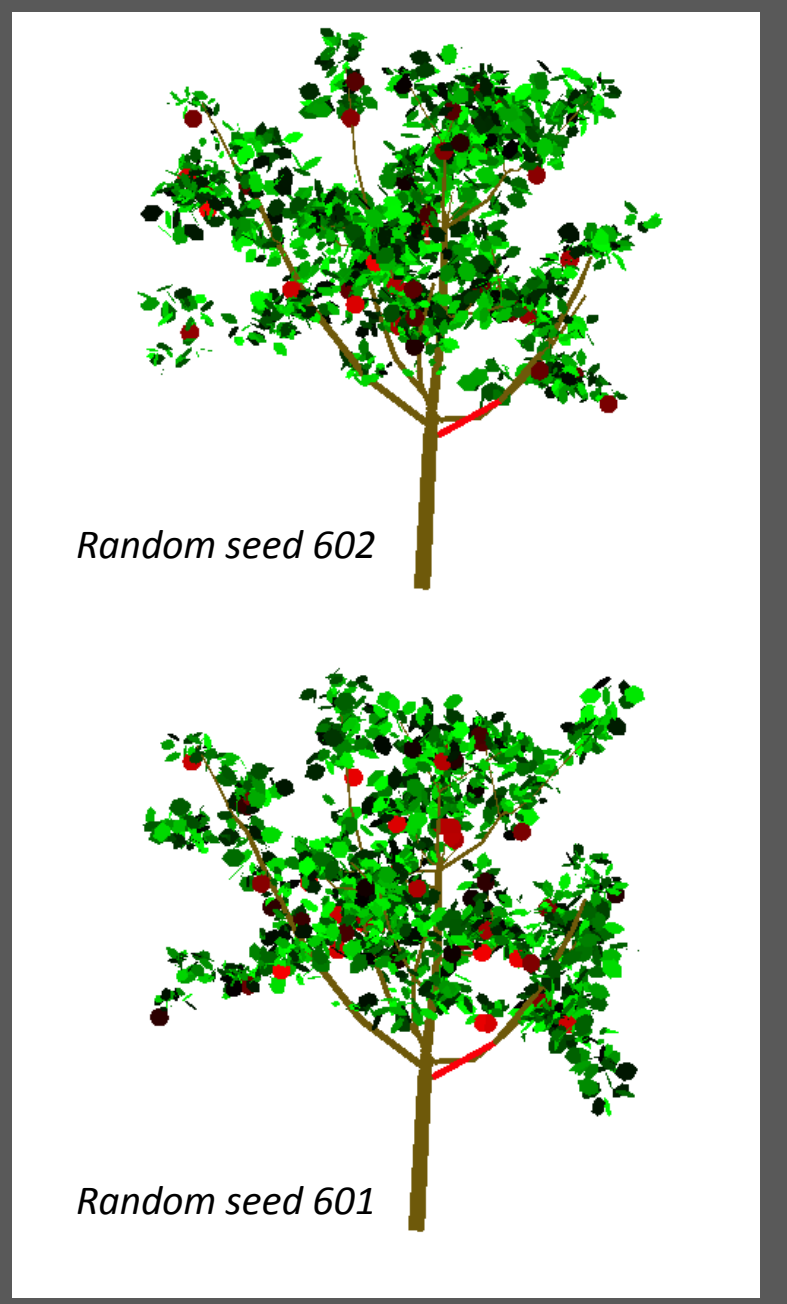




\section{Model validation, light interception inside the canopy (tree 1)}

\section{- Observed tree}
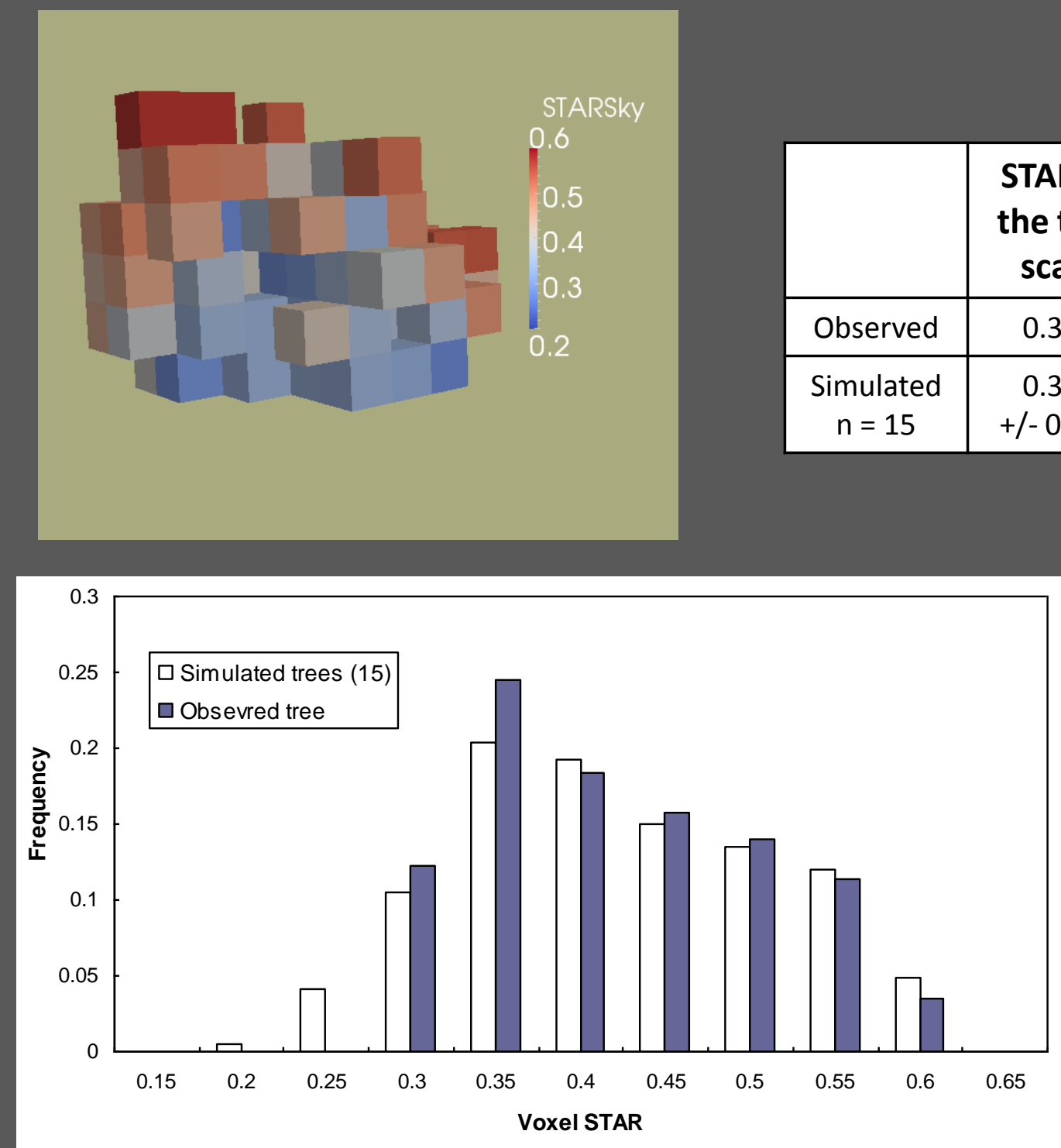

- Simulated trees

\begin{tabular}{|c|c|}
\hline & $\begin{array}{c}\text { STAR at } \\
\text { the tree } \\
\text { scale }\end{array}$ \\
\hline Observed & 0.350 \\
\hline $\begin{array}{c}\text { Simulated } \\
\mathrm{n}=15\end{array}$ & $\begin{array}{c}0.349 \\
+/-0.011\end{array}$ \\
\hline
\end{tabular}

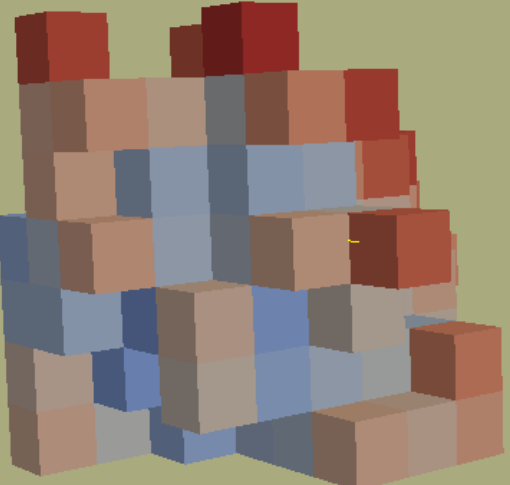

Random seed 602

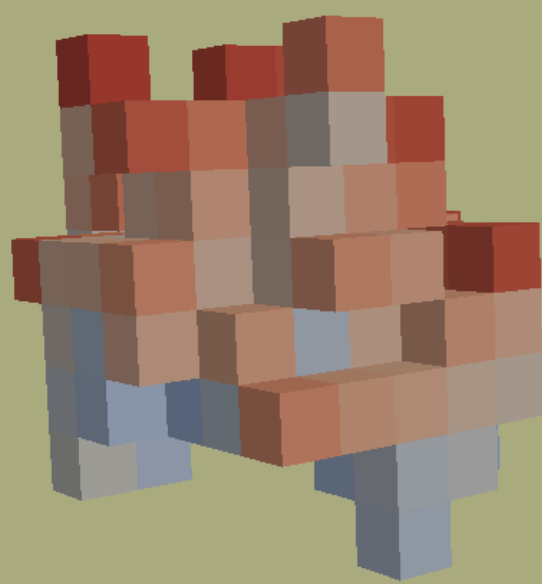

Random seed 601
STARSky

STARSky 0.6

0.5 


\section{Model validation, shoot demography and leaf area (tree 2)}

\section{- Observed tree}

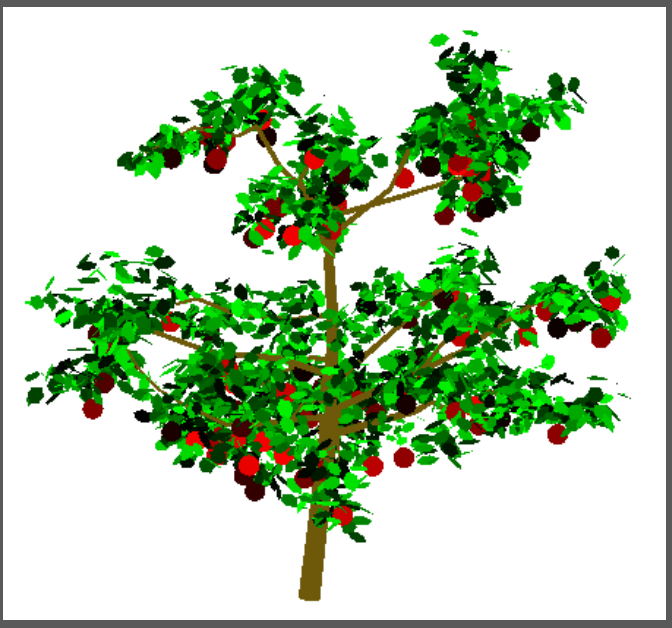

- Simulated trees

\begin{tabular}{|c|c|c|}
\hline & $\begin{array}{c}\text { Leaf area } \\
\left(\mathbf{m}^{\mathbf{2}}\right)\end{array}$ & $\begin{array}{c}\text { GU } \\
\text { number }\end{array}$ \\
\hline Observed & 4.42 & 451 \\
\hline $\begin{array}{c}\text { Simulated } \\
(\mathrm{n}=15)\end{array}$ & $\begin{array}{c}4.60 \\
+/-0.18\end{array}$ & $\begin{array}{c}492.1 \\
+/-26.2\end{array}$ \\
\hline
\end{tabular}

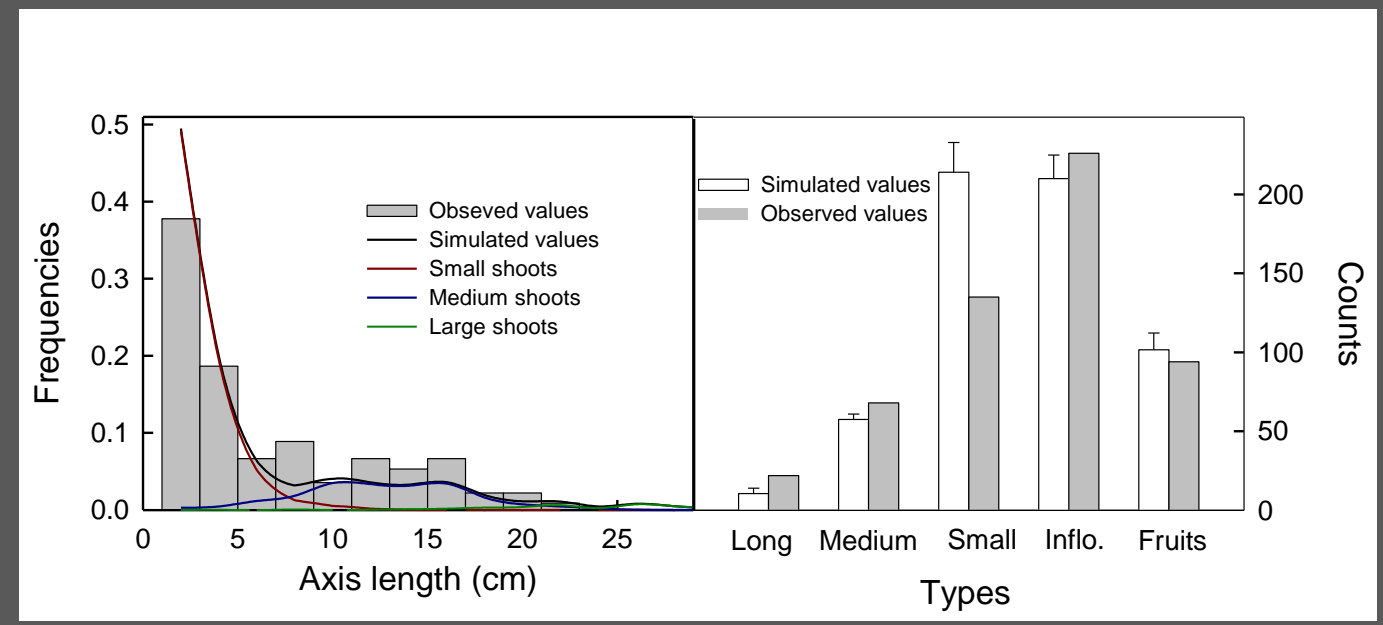

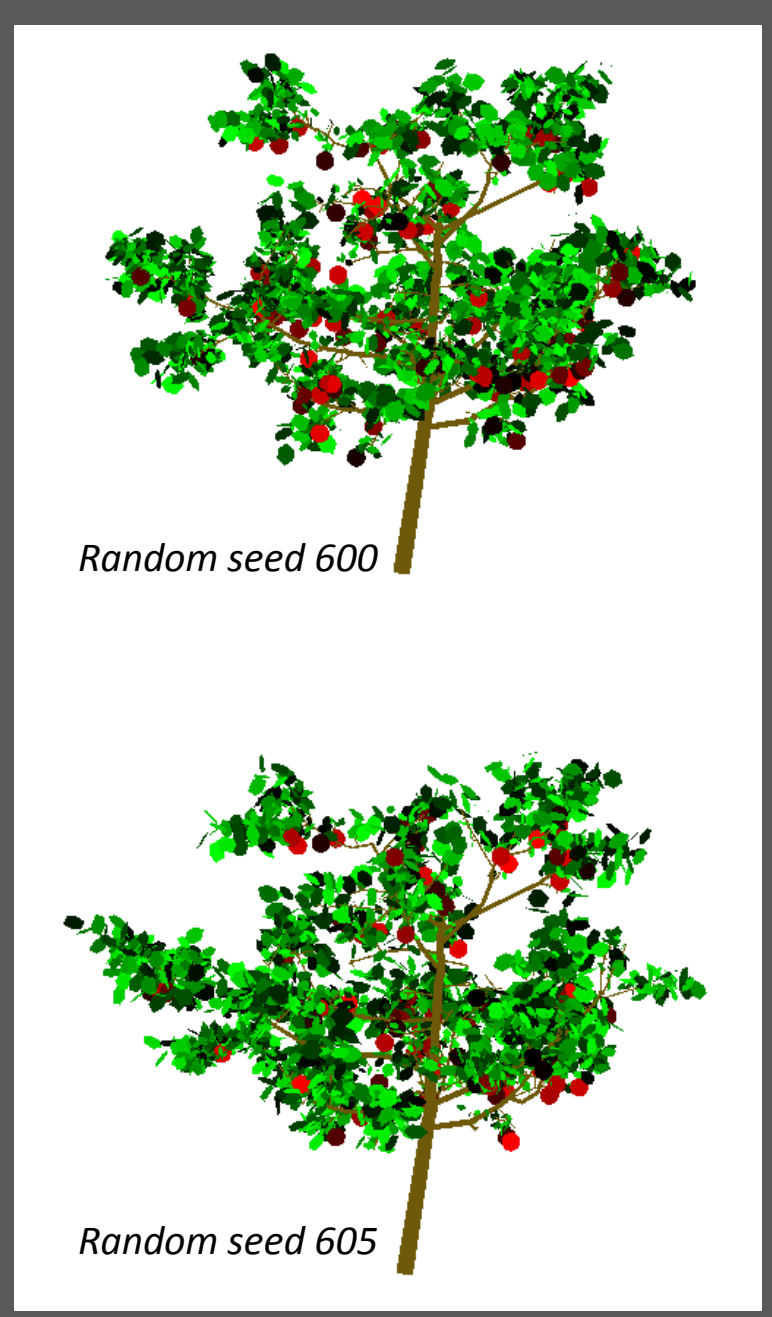




\section{Model validation, light interception inside the canopy (tree 1)}

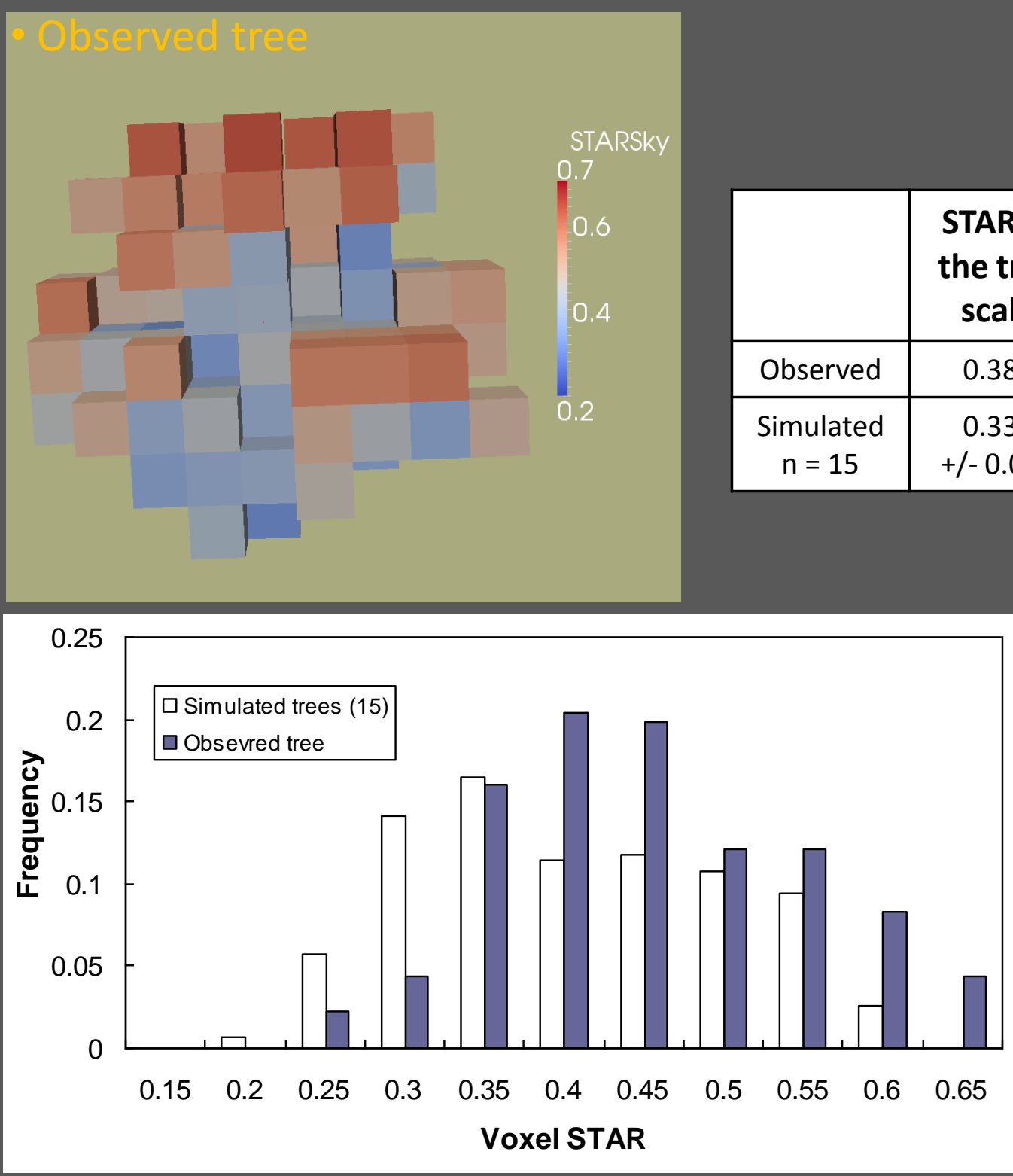

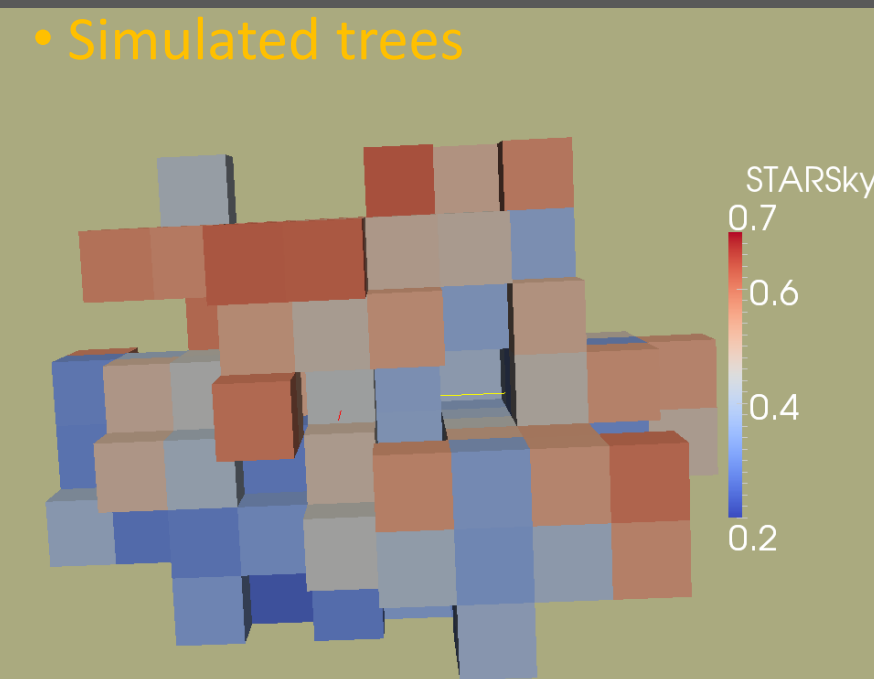

Random seed 600

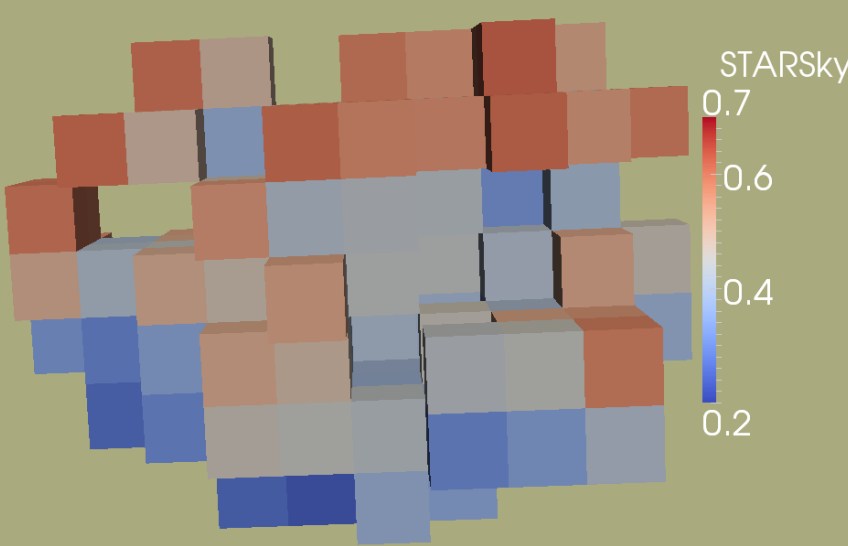

Random seed 605 


\section{Multi-years simulations}

- The model is able to simulate tree growth over years.

- 2015 digitizing data are needed to validate the model on a 2 years time step

- The tree response to pruning should be integrated.

- A branch bending submodel (Costes et al. 2008) should be integrated to simulate branch geometry over years

End 2013

(observed tree)

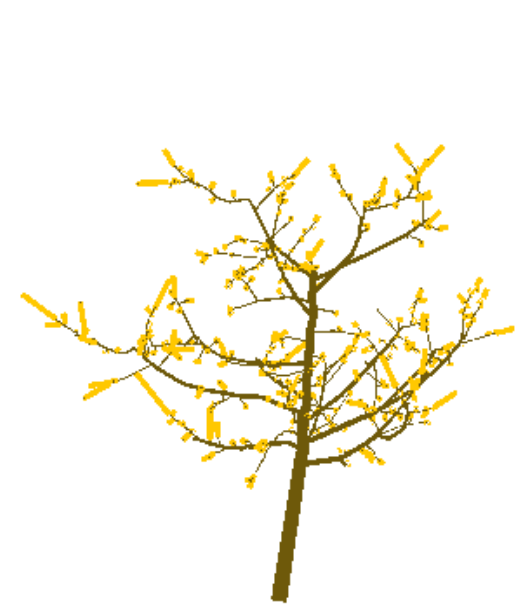

2014

(simulated tree)

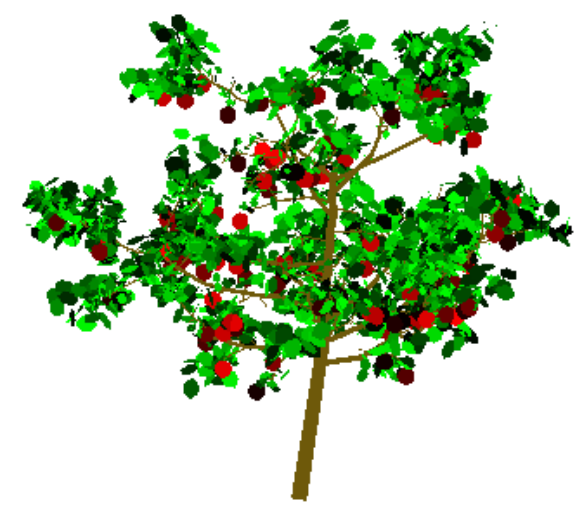

2015

(simulated tree)

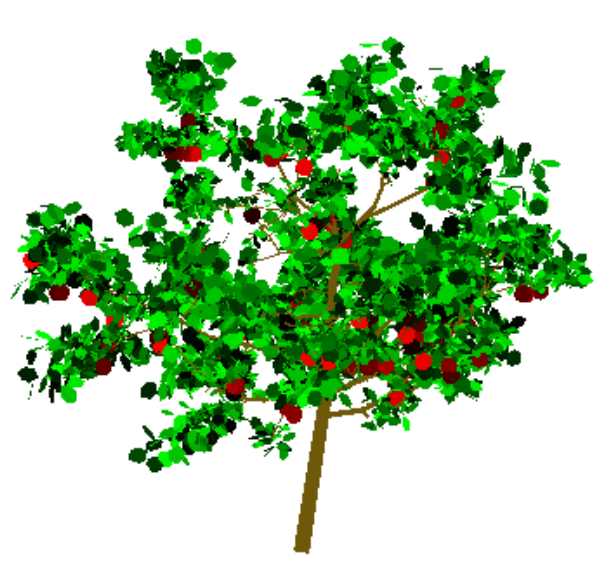

2016

(simulated tree)

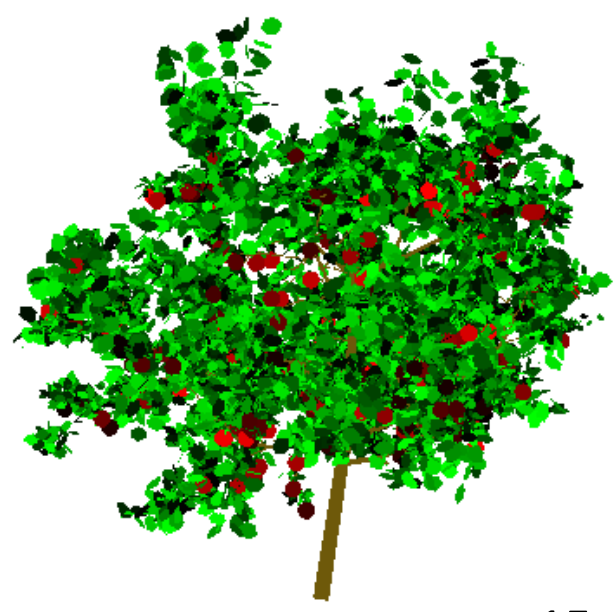




\section{Conclusions and perspectives}

Development of a new modelling approach

- Including and adapting already used statiscal models

- Linked with a light interception model

- Allowing the valorisation of time consuming digitizing data.

First calibration of the model

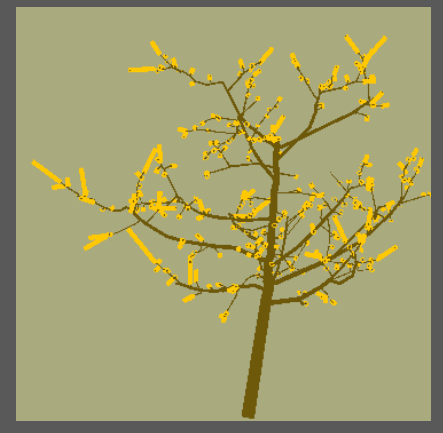

- On Jubilé cultivar (old tree).

- At different scales (whole tree, voxels)

Limits and forthcoming works.

- Model calibration is time consuming

- Testing the relevance of multi-years simulations

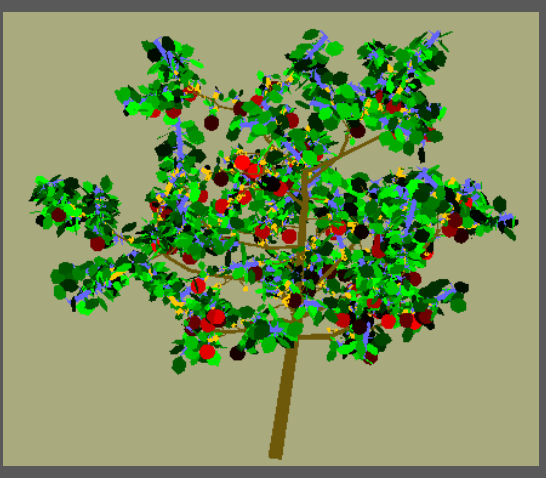

- Testing the generecity of model parameters for other tree ages

- Necessity to take into account pruning to deal with agronomic cases of study.

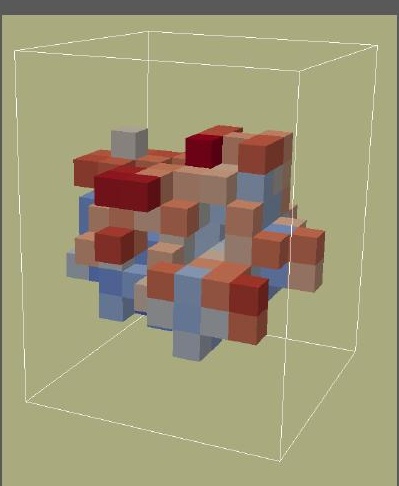




\section{Thanks you for your attention}

Acknowledgements:

- AFEF team of UMR AGAP

- UMR PIAF

Simulated tree P1

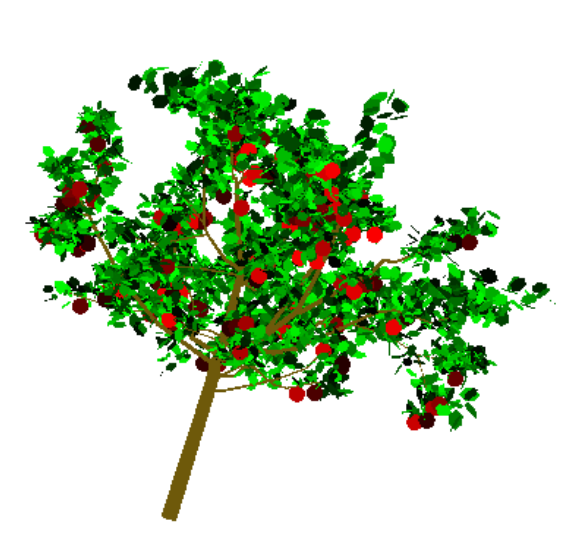

Simulated tree $P 2$

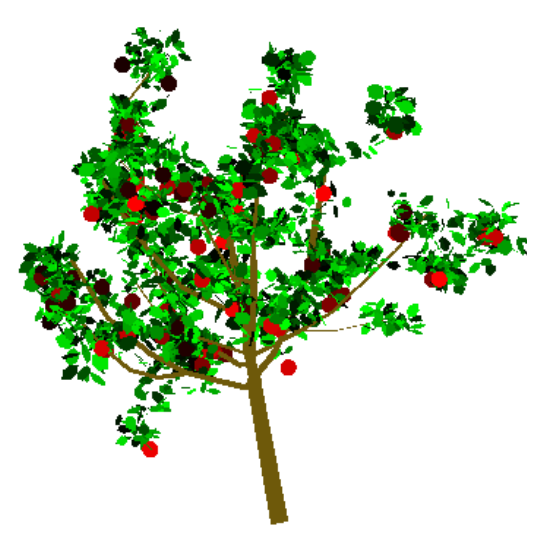

Simulated tree P3

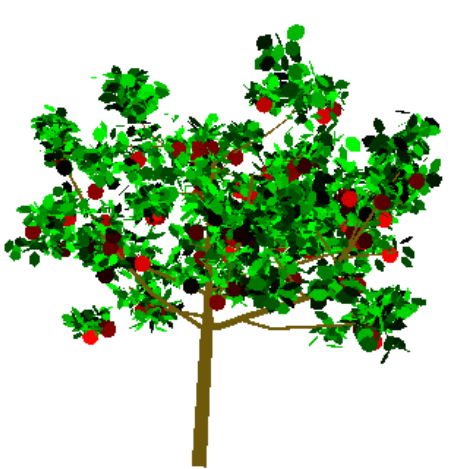

Simulated tree P9

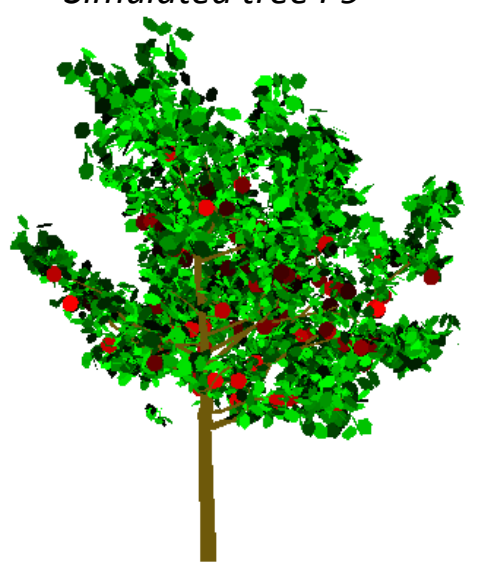

Simulated tree P10

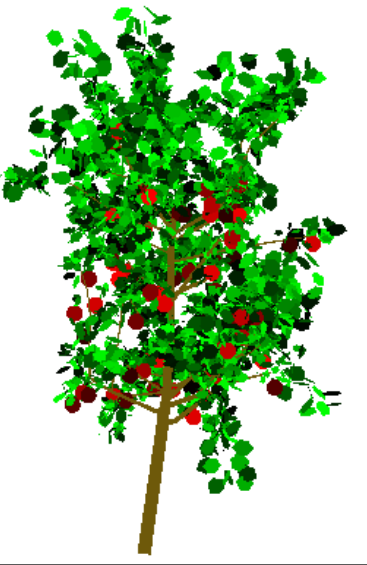

